medical diagnosis and treatment has presented new problems in all phases of radiation protection; and recommended standards of safety, intended primarily for the protection of the radiation worker and not for the patient, are concisely set forth in the new handbook. Rules are given for working conditions, survey and inspection of installations (fluoroscopic and fluorographic, dental, diagnostic and therapeutic) and structural details of protective barriers, and a chapter is devoted to electrical protection. Useful tables, graphs and instructions for determining the thicknesses of protective barriers and the distances required for protection in air are included. The permissible dosage-rate is taken as 0.300 roentgen per week.

\section{White Plaster Mould of Mushroom Beds}

A sUCCINCT account of Scopulariopsis fimicola, a fungal competitor on mushroom beds, is to be found in Bulletin No. 16 (July 1949) of the Mushroom Growers' Association. Infection is probably brought by air-borne spores and by flies. An interesting feature is the control by addition of superphosphate -14 lb. per ton of fresh manure-or watering with $1 \mathrm{Ib}$. per gallon of water.

\section{Polymer Chemistry as Applied to Plastics}

THe Plastics and Polymer Group of the Society of Chemical Industry has arranged a symposium on "Polymer Chemistry as Applied to Plastics", to be held in the Beveridge Hall, University of London, during September 21-23. Prof. E. K. Rideal will open the symposium, which will consist of four sessions as follows: September 21 (aftermoon), the tools of polymer research; September 22 (morning), relationship between structure and properties of polymers; September 22 (afternoon), polymerization and polycondensation (theory); and September 23 (morning), polymerization and polycondensation (in practice). Each of the four sessions will involve the presentation of about six papers, which will be followed by general discussion, and shortened versions of the contributions will be printed and distributed beforehand to subscribing participants. The registration fee is $10 s$. to members and $£ 22 s$. to non-members of the Society. Further information can be obtained from Dr. N. J. L. Megson, Hon. Organising Secretary, Ministry of Supply, Room 716, Shell Mex House, London, W.C.2.

\section{International Federation of Electroencephalography and Clinical Neurophysiology}

Is September 1949 the International Federation of Electroencephalography and Clinical Neurophysiology was formed, its objective being : "To stimulate, assist and co-ordinate research and investigation; and to improve clinical practice in the field of electroencephalography and clinical neurophysiology, to maintain close liaison with other scientific bodies or agencies and with United Nations organisations; and to provide a central clearing house for distribution of information through correspondence with the secretariat, organisation of international meetings and publication of an international journal, Electroencephalography and Clinical Neurophysiology". Officers of the Federation elected for the term of three years until the third International Congress to be held in the United States in June 1952 are as follows : Honorary President, Prof. E. D. Adrian; President, Dr. Herbert H. Jasper; Vice-Presidents,
Dr. Robert S. Schwab, Dr. W. Grey Walter and Dr. Fritz Buchtal ; Secretary, Dr. Henri Gastaut; Treasurer, Dr. Antoine Rémond. All correspondence should be addressed to Dr. H. Gastaut, Sec., Int. Fed. of EEG Societies, 149 Prom. de. la Corniche, Marseille, France.

\section{University of London: Appointments}

THE following appointments in the University of London have been announced: Dr. M. L. Rosenheim, to the University chair of medicine, tenable at University College Hospital Medical School, from April 1, 1950 ; Prof. Isaac Schapera, to the second University chair of anthropology, tenable at the London School of Economics and Political Science, from October 1, 1950 ; and Dr. D. M. A. Leggett, to the University readership in mathematics, tenable at King's College, from October 1, 1950.

\section{Institute for Medical Research, Kuala Lumpur}

Mr. John W. Freld, Institute for Medical Research, G.P.O. Box 1005, Kuala Lumpur, Federation of Malaya, states that during the Japanese occupation the Institute lost portraits of several of its former directors. It was hoped to use these in a fifty-year series of portraits for a memoir to mark the Institute's half-centenary this year. Portraits are wanted of Dr. Hamilton-Wright and Dr. Henry Fraser. Dr. Wright left Malaya in 1903 and died in Washington, D.C., in 1917. Dr. Fraser retired in 1916 to live in Scotland, where he died in 1930. Mr. Field would like to get into touch with surviving relatives.

\section{Announcements}

Sir IAN Heillbron, director of research of the Brewing Industry Research Foundation and emeritus professor of organic chemistry in the University of London, has been appointed chairman of the Advisory Council for Scientific and Industrial Research in succession to Sir Geoffrey Heyworth, who resigned owing to pressure of other public duties.

The Platinum Medal for 1950 of the Institute of Metals has recently been awarded to the distinguished French metallurgist, Prof. Albert Portevin, in recognition of his eminent services to the science and practice of non-ferrous metallurgy. Prof. Portevin is professor at the Ecole Supérieure de Soudure Autogène (Paris); most of his investigations have been on physical metallurgy, particularly of steels, but much of the work on foundry problems, corrosion and inclusions is equally of importance for non-ferrous alloys.

Prof. J. Z. Young, professor of anatomy, University College, London, is to deliver the Reith Lectures for 1950 of the B.B.C. during the autumn; he will speak on "Doubt and Certainty in Science".

Prof. Read has been invited, as the first winner of the Cortina-Ulisse Prize (Nature, 164, 605; 1949), to lecture in about a dozen Italian centres, ranging from Turin to Naples, during May. The lectures will deal with researches in organic chemistry and stereochemistry and also with certain cultural aspects of science.

ERratum. In the article in Nature of April 1, p. 517, on "World's Food and Britain's Neods", Mr. F. Le Gros Clark is reported as saying that "Agriculture has the problem of increasing output fifty to a hundred times in the next fifty years". This should read, "increasing output by 50-100 per cent". 